\title{
Orthostatic headache and bilateral abducens palsy secondary to spontaneous intracranial hypotension
}

\author{
Jesús Porta-Etessam • Daniela Di Capua $\cdot$ \\ Manuela Jorquera $\cdot$ Maria-L. Cuadrado • \\ Azahara Marcos
}

Received: 8 June 2010/ Accepted: 17 September 2010/Published online: 30 September 2010

(C) Springer-Verlag 2010

\begin{abstract}
Spontaneous intracranial hypotension (SIH) is a well-documented syndrome characterized typically by a benign, self-limited course. Patients typically present with postural or exertional headaches that can be temporarily relieved by lying in a supine or recumbent position. A 35year-old Caucasian male suffered orthostatic headache that developed to a bilateral abducens palsy. We ordered relative rest and the patient improved and completely recovered after 3 months. Although SIH is considered as a benign and self limited process it could also be associated with disabling complications. We should be aware of the possible complications and inform our patients. SIH can present with headache and bilateral abducens palsy even when the headache is improving.
\end{abstract}

Keywords Spontaneous intracranial hypotension . Headache $\cdot$ Bilateral abducens palsy

J. Porta-Etessam · M.-L. Cuadrado

Headache and Neuro-Ophthalmology Unit,

Neurology Department, Hospital Clínico Universitario San

Carlos, Madrid, Spain

D. Di Capua · A. Marcos

Neurology Department, Hospital Clínico Universitario San

Carlos, Madrid, Spain

M. Jorquera

Radiology Department, Hospital Clínico Universitario San

Carlos, Madrid, Spain

J. Porta-Etessam ( $\square)$

C/Andrés Torrejón, 15, 7, 28014 Madrid, Spain

e-mail: jporta@yahoo.com; mporta@caminos.recol.es

\section{Introduction}

Spontaneous intracranial hypotension (SIH) is a well-documented syndrome typically characterized by a benign, self-limited course [1]. Patients typically present with postural or exertional headaches that can be temporarily relieved by lying in a supine or recumbent position [1]. Other common symptoms are nausea, vomiting, neck stiffness, altered hearing, or less frequently visual obscurations or double vision [2]. We present a case of a 35-yearold man with SIH who developed double vision due to bilateral sixth cranial nerve palsy.

\section{Case report}

A 35-year-old Caucasian male, with normal complexion and without any interesting disease, suffered an intense $(9 /$ 10) and progressive headache during his holidays in Japan. The patient did not remember any exertion, heavy lifting, sneezing or straining before the headache started. The headache was severe in upright position, and disappeared when he laid flat. The headache was holocranial, pulsating, and severe. Headache was accompanied by nausea, and photo but not phono or osmophobia. There was no fever or other systemic symptoms. He denied any cranial trauma, rhinorrhea or otorrea. After 7 days of intense and progressive headache he started to improve (6/10). 10 days since the beginning he developed double vision and decided to advance the return of his holiday. on admission he referred an orthostatic headache and binocular double vision. There were no other symptoms. His clinical picture fulfilled International Headache Society diagnostic criteria (ICHD-II) for intracranial hypotension [3]. On examinations he presented a double six palsy (Fig. 1) and we 
Fig. 1 Ocular movement showing a bilateral limitation in abduction
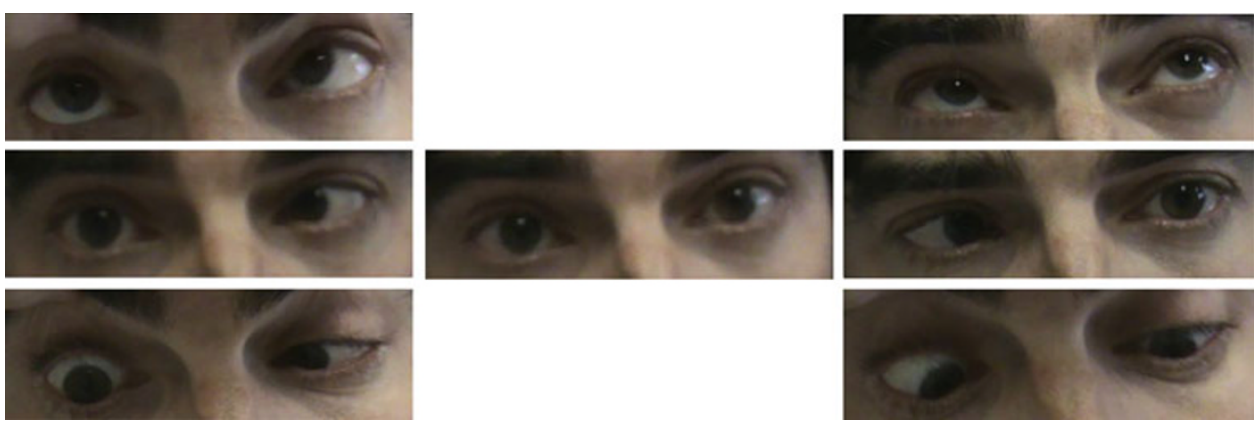

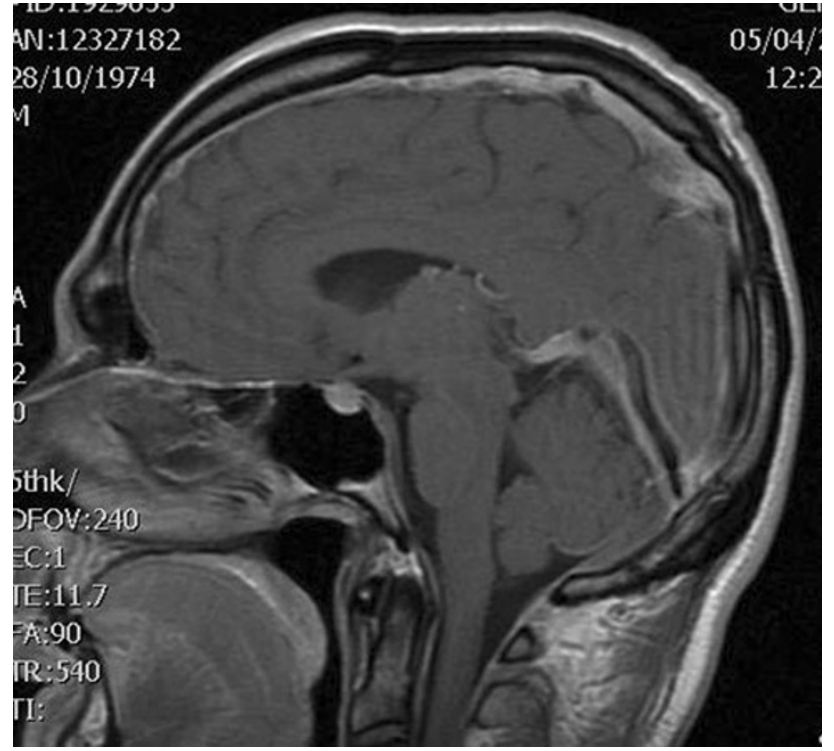

Fig. 2 Cranial MRI showing diffuse meningeal thickening and gadolinium enhancement

induced an increase of the headache by pressing his jugular veins. Magnetic resonance imaging (MRI) of the brain demonstrated typical features of intracranial hypotension [4], diffuse thickening and gadolinium enhancement (Fig. 2) of the pachymeninges and pituitary enlargement. We put our patient on analgesia and relative rest at home. After 2 weeks he started to improve and the headache disappeared and after 3 months he has recovered from abducens palsy.

\section{Discussion}

Changes in intracranial pressure are a known cause of headache. Included in the classification of the IHS, intracranial hypotension is usually secondary to head trauma or lumbar puncture [3]. SIH is less frequent and most of the cases have no antecedent events; several authors have suggested that these cases are a result of a dural tear or leak that could be related with exertion or a Valsalva maneuver.
The most frequent symptom is the headache that is elicited or exacerbated by the upright position. Other common symptoms are nausea, vertigo or tinnitus, photophobia and nuchal rigidity. In some cases the patient could suffer pontine flattening and pressure of the pons against the clivus, subdural hematomas confusion and even coma [1]. Cranial nerve palsies, often resulting in ophthalmoplegia, have been reported to occur with symptomatic SIH [5]. The precise pathophysiology of the cranial nerve paresis in SIH remains to be determined [2]. Most accepted explanation is the traction on the cranial nerves due to the downward displacement of the cranial contents $[3,6]$. The most common ophthalmoplegia encountered is an abducens nerve paresis, which in majority of the cases is unilateral. The abducens nerve is more likely to be susceptible to the traction-related injury secondary to its long intracranial course along the clivus and through the Dorello canal, as well as its attachment to the Gruber ligament [7]. Another hypothesis could be pontine sagging against the clivus, but we have not seen any important pontine flattening in the MRI.

Although SIH is considered as a benign and self limited process it could also be associated with disabling complications. In our case with relative rest the patient improved. We should be aware of the possible complications and inform our patients. SIH can present with headache and bilateral abducens palsy even when the headache is improving.

\section{Conflict of interest None.}

\section{References}

1. García-Morales I, Porta-Etessam J, Galán L, Lagares A, Molina JA (2001) Recurrent subdural haematomas in a patient with spontaneous intracranial hypotension. Cephalalgia 21:703-705

2. Zada G, Solomon TC, Giannotta SL (2007) A review of ocular manifestations in intracranial hypotension. Neurosurg Focus 23:E8

3. Headache Classification Subcommittee of the International Headache Society (2004) The international classification of headache disorders: 2nd edition. Cephalalgia 24(Suppl 1):9-160 
4. Alvarez-Linera J, Escribano J, Benito-León J, Porta-Etessam J, Rovira A (2000) Pituitary enlargement in patients with intracranial hypotension syndrome. Neurology 55:1895-1897

5. Khemka S, Mearza AA (2006) Isolated sixth nerve palsy secondary to spontaneous intracranial hypotension. Eur J Neurol 13:1264-1265
6. Niedermüller U, Trinka E, Bauer G (2002) Abducens palsy after lumbar puncture. Clin Neurol Neurosurg 104:61-63

7. Berlit P, Berg-Dammer E, Kuehne D (1994) Abducens nerve palsy in spontaneous intracranial hypotension. Neurology 44:1552 